\title{
Leveraging Social Media for Development in Organisations
}

\author{
Ajith Sundaram ${ }^{1,2}$ \\ ${ }^{1}$ Research Scholar, Anna University. Chennai, India \\ ${ }^{2}$ Assistant Professor, Rajagiri Centre for Business Studies, India \\ Correspondence: Ajith Sundaram. E-mail: ajithsundaram@gmail.com
}

Received: February 14, 2017

Accepted: March 2, 2017

Online Published: March 24, 2017

doi:10.5539/ass.v13n4p201

URL: https://doi.org/10.5539/ass.v13n4p201

\begin{abstract}
Marketers must never underestimate an online buyer. If they are assuming that mere marketing efforts from their side will influence a buyer, then they are being uncalculated and ignorant. Potential customers are not isolated people who are glued to their computer systems confused as to what product to buy. Instead they are tech-savvy, socially active, smart buyers who make a detailed analysis about the product they intend to buy online. Therefore, marketers need to re-design their online marketing strategies to suit to the needs of the buyer. The marketing approach should focus on social influence marketing as well.
\end{abstract}

Keywords: Social Media Marketing, Facebook, YouTube, Social Influence Marketing

\section{Introduction}

To begin with, let us define Social Influence Marketing-a system that encompasses social media and social influencers to accomplish their business objectives. Social media is termed as those online applications, platforms and media which aim to simplify interactions, collaborations and content sharing. In social media information is created and catered to its users by its users. In short, it is a democracy on the internet. Information, in this context, refers to the comments posted, photos or videos shared, blogs, conversation, etc. There has been enough evidence to prove that the social networking sites have become the typical online media. Social network sites has the most audience compared to any other media tools. Social Influencers are those who have the power to create a huge impact on their peers by way of their content disseminating features. They can be anyone starting from a spouse, a friend, a colleague or a product reviewer, who have a major influence on the decision making process of the buyer. In simple terms, social influencers are those who are directly or indirectly associated with the brand affinity or buying decision process. They may be doing this intentionally or unintentionally through their participation on social media platforms by posting reviews or commenting about the products.(Fire, Goldschmidt, \& Elovici, 2013)

Social influence marketing deals with the identification and understanding the influencers of the buyer and his needs. The terms social influence marketing and social media marketing are used interchangeably, however, there is a subtle difference. The former focusses on the influencers of the buying process whereas the latter focusses on the ads on social networking sites like Facebook, Twitter, etc. (Fire et al., 2013; Guthrie, Cuganesan, \& Ward, 2008)

\subsection{Understanding the Fundamentals of Influence}

Long before Web came into existence, people were easily influenced and motivated by fellow human beings. They relied on the advice and experience of others before buying a product. Whenever a product was described in a positive light, it inspired people to buy it. The degree to which a person can be influenced is determined by multiple factors. Undoubtedly, the product worth being the first. Goods can be low-consideration purchases that is, low involvement goods or those with less risk and high consideration purchases that is, high involvement goods or those with more risks. In those that involved low-consideration purchases, opinions hardly matter and people do not seek others advice as the products are less expensive goods. On the other hand, for those that involved high-consideration purchases, for example, a high value product like a motor-car, people seek the advice and opinion of many, in person and online. This is where social influencers have a much larger role to play. People do not want to be the first to try a product and take a risk especially in high worth goods. Most consumers are of the opinion that they are at a safe zone when they take the advice, feedback and experience of others who already used it before them. So a marketer should be aware about which influencer to influence first 
at the time of marketing. So in addition to giving a product description and advertisement to the consumers, the marketer should first choose the type of influencer to target his advertisement. Basically social influencers can be classified into three types- referent, expert, and positional. (Wey, Blumstein, Shen, \& Jordán, 2008)

Referent influencer-A referent influencer is someone who is active on social platforms. They belong to the consumer's social circle and have an impact on the purchasing decision of others through their reviews, status updates and comments in blogs and community platforms. As the consumers know some of these influencers personally, there is a credibility in their interaction and people are easily influenced by their advice and opinions and consider them as meticulous analysers. They hold a grip on the consumers because of their relationship with them. In spite of reviewing the products through their own sources, consumers trust and rely on these influencers for purchase decisions.(Guthrie et al., 2008)

Expert influencer- An expert influencer or key influencer is a genius who knows the nuances of product performance. Expert influencers are considered an authority on the product who may not know their audience personally. They have a huge fan following and have their own blogs where their guidance and advice can be sought. They pass their judgement about the product on review sites and rate and rank products given their skill and expertise acquired out of their experience or their association with the organization. (Patchin \& Hinduja, 2010)

Positional influencer- A positional influencer or peer influencer is in a close relationship to the buyer. They typically belong to the consumer's inner circle, may be a family member or a close friend. They have the direct influence on the buyer in his decision making process and they may also directly associated in the usage of the product. Their opinions have the highest priority and has the most social influence.(Barrutia \& Echebarria, 2013)

Therefore, each time a person intends to buy something, a guidance or opinion is got either from an expert or from a known person. We may wonder why there is such a huge discussion on influencers. That is because the rise of social media sites have been phenomenal and the number of visitors and users accessing these sites have reached around 175,000, considering just a single site, Facebook, alone. People are crazily buying online. There are more and more buying happening online every day. People buy clothes, shoes, grocery, mobile phones, televisions, computer, jewellery and cars too. Apart from making online purchases, people discuss about it, review the products, recommend them if it delights them, ultimately influence some online user into buying or not buying on a much larger scale. People's real world decisions are shifting to the internet in an unfathomable manner. Social media platforms like Facebook, LinkedIn, Twitter, You Tube, Instagram, Yelp, etc, are some of the few websites where people seek help from other users through guidance, reviews and recommendations. Shrewd marketing practices nowadays focus on redesigning the company websites to enable customers bring in their social influencers into purchase process. Companies have realised that buying is no more an isolated activity. People, too, were accustomed to this group decision making long before internet marketing became popular. Hence social influence marketing has become inseparable part of any promotion campaign.(Gneiser, Heidemann, Klier, \& Landherr, 2009)

Even today, some managers need to be coaxed into investing in online marketing campaigns. A lot of effort is needed in convincing them how viable and cost effective the social media platforms are. Though many feel that internet is a youth sensation, it is the best medium to communicate about the brand and establishing credibility.

\subsection{Comparing Social Influence Marketing with Other Marketing Efforts}

However, marketers must not ignore the traditional marketing methods like direct mail, advertising on television, in print, public relations, etc. Social marketing will not be a success when carried out in isolation. It has to be integrated with the mainstream channels of advertising. Those employees who deal in conventional marketing campaigns need to be reassured that social influence marketing complements their marketing efforts. They should not be alienated though some of the social influence marketing tactics are not in sync with the traditional channels. When other forms of marketing practices are disregarded and discredited, business may be affected in the long run. As of now, there is a need to discuss the traditional marketing procedures.(Chu \& Kim, 2011)

Direct mail: Direct mail is about interacting with an active customer database and initiating promotion activities by means of circulars, catalogues, door delivering merchandise. Direct mail is the most efficient mode of personalised and targeted marketing. Though direct mails are a nuisance at times, it is successful when used for communicating about offers. The catalogue industry which had been making a lot of money through this direct mail system is likely to suffer losses once social influence marketing gains momentum. In today's scenario, with more and more people opting to connect with their influencers before making a purchase, there are little chances of them trusting a flyer in a direct mail or what the company website boasts about the product. People would rather get a review from a peer than browse through the direct mail. Direct mail started losing its credibility as 
most of them have stopped trusting the promotion campaigns of the marketers and have started depending on feedbacks from influencers. There is anyway, another side to the story. People get to know more consumers through social marketing. This can be created into a database for direct mail which is like opting to receive mails in exchange for information and membership in an online community. Direct mails, though have lost favour among consumers, are still regarded as a starting point for an online community or for rewarding members through mailing coupons. (Anon, 2000)

Public relations (PR): Public relations professional were the early advocates of social media marketing. They were tech savvy experts and some of them equated social media as the traditional media and carved a niche in this space. They, with their acumen, identified the influencers and bestowed exclusive privileges upon them. PR professionals tracked the comments and interviews of influencers to study how much recognition their brands got. In fact, these influencers were PR professionals earlier and they recognised the potential of social media before anyone else did. They used social media to complement a company's PR efforts. However, there is a complex relationship between PR and social media. PR deals more with traditional media and aims at pushing the company's objectives to the press and amplify the message. But social influence marketing is more of influencers influencing potential users. So on a social media platform, influencers have a much powerful status than a PR expert. Although, PR professionals push the company's message on social media realm which conflicts with the social influence marketing. The company must also keep in mind their PR goals and ensure that there is no contradiction when they take to social media marketing. For this, PR members of the company can interact with the influencers and device strategies for marketing. For PR professionals, social influencing marketing is just an extended, updated, technical version of the job they do offline.(Jiang, 2006)

Display advertising: Display advertising refers to those sites where marketers promote their products after identifying the online behaviour of the customers. They identify those sites which are frequented by target customers, buy some space online, design ads on it and finally measures the effectiveness of the ad campaign by calculating the number of times the ad was viewed and shared. The process in itself is very cumbersome, starting from identifying the most frequented site, buying space, analysing the worth of money spent on the ad on the platform and if it has produced the desirable effect. But the highlight of display ad is that the success of the advertisement can be measured as compared to those on television and print. The relationship to social influence marketing is analysed and the following are some of the linking points.(Provost, Dalessandro, Hook, Zhang, \& Murray, 2009)

Market to the social influencers who surround the customer, as well as the customer: One way to market to the influencers is by using display ads on sites that not only the customer visits but also those that influencer visits. The effectiveness of the ad, in this case, is difficult to measure as the influencers may not purchase the product themselves but may remember the ad and influence the buying process of others.(D. Boyd, 2008)

Place display advertising on the social platforms - like Facebook, MySpace, and YouTube — that your customers frequent: Social media sites accept display advertising in many forms, generating a chunk of their revenue. In spite of presenting poor results, as the users hardly notice the advertisements, newer ad formats are emerging. For instance, a concept called 'Appvertising' is gaining popularity. It is an advertisement within an application that are available on social network. These are found to yield better results. Another feature is requesting the consumers to rate the quality and content of the advertisement they are viewing. This method is for identifying the appropriate target audience.

Use interactive, social advertising: Nowadays, marketers have become innovative where they post an advertisement in a leading and popular website. Audience are invited to react to some queries within the ad entity. One can see responses of other users in this entity. This is a perfect example of ad entity becoming an avenue for interaction.

Promotions: Promotions is a type of marketing activity that is most affected due to social influence marketing. Promotions are marketing efforts undertaken by the company where the customers are incentivised to stimulate product purchase. Promotion primarily involve contests, rebates, samples, sweepstakes and discounts. As more of interactions are taking place on social media sites, people hardly pay attention to promotional offers or are uninterested in spending time on these. However, marketers have identified the potential of social influence marketing in such scenario. By engaging social influence marketing concepts, promotional strategies can be designed to attract social influencers. With the participation of a social influencer, marketers expect that their participation would influence others to get stimulated into trying the offers.(D. M. Boyd \& Ellison, 2008)

Marketing via Niche Networks and Online Influencers: Marketers are expecting that social activity would move beyond just Facebook, Twitter, YouTube and MySpace. There would be greater disintegration of user created 
data and there would be uninterrupted flow of information between major media sites and the rest of internet. MySpace, Facebook, Classmates, MyLife and Buzznet top the list of most visited social platforms as on February 2009. Rather than merely focussing on major social media platforms, marketers can consider advertising on niche platforms, as customers spend an equal time on these too.

Finding the Right Social Platforms: It is a real challenge for the marketers in identifying where the potential customers are spending their time on. Marketers need to look at various other avenues beyond the social media sites. Customers may be online in video websites, blogger networks, mainstream media sites and social publishing applications.

Classifying the social platforms: On the basis of size and growth rate, four major social platforms are identified. They are Facebook, MySpace, YouTube and Twitter. Some of the major media and entertainment sites have accommodated so much functionality that they are entitled to be called platforms. Next classification is niche social platforms. It focusses on a narrow set of audience and subject. These sites like LinkedIn and CafeMom concentrate on a niche market and are the masters of owning it. The social platform infrastructure providers are those category that enable users to create their own blogging space. It has community pages, member spaces and activity areas. Finally, there is the blogosphere. Blogging sites have featured in the list of top entertainment sites. Blogs have no formal relationship with each other but features like trackbacks, comments and reciprocal networking bind them together. So marketers can focus on major social platforms, niche social platforms, social infrastructure providers and blogospheres when they are looking to market to potential customers.

Understand your customers: Marketers can identify the online behaviour of the customers through a technique called socio-technographics (the way in which customers engage on social media). The process starts by knowing the engagement level of the customers on the web. With the help of Forrester Social Technographic Tool, profiling of customers can be done, after which, the tool gives an analysis of the customers. Customers are divided into creators, critics, collectors, joiners, spectators and inactives. Another tool Quantcast gives the audience profile of a social platform. The third type of study is by interacting with customers directly. Study is conducted on how and where socialisation takes place. A sample of users are interviewed which can generate almost accurate insights regarding social behaviour. The live responses of the customers regarding the product, brand or company is obtained. However, it is imperative for the marketers to be abreast of research activities as online social behaviours are dynamic. They need to run a parallel program on ongoing social research to be ahead of the changes.(Papacharissi, 2009)

\subsection{Research the Platforms}

The dynamics of each social media platform need to be thoroughly understood to predict and design the social influence marketing strategy. Lack of awareness may render the marketing campaign futile. Though there are no specific guidelines for advertising in each site, the advertising industry have begun to establish formats. Social Media Subcommittee of Interactive Advertising Bureau is working on streamlining those aspects that go into the making of advertising on social sites. Marketing strategies on social platforms are still in their embryonic stage, however innovative practices are setting benchmarks for effective advertising. Advertising layouts cannot be all-inclusive. They can be classified as

- Traditional display advertising- the usual banners that we see across the internet. They have cookie-based performance and are treated as traditional display banners and measured mainly through cost per impressions(CPM) or click through rates (CTR)

- Social advertisements- a person's social graph is depicted on the ad entity encouraging involvement. The social advertisement include user created data and are directed towards friends in a network.

- Sponsorships- works on the principle of pay per post format where bloggers are motivated to discuss on relevant topics. The bloggers have utmost autonomy over the content in addition to minute guidelines.

- Influencer marketing-Some social platforms enable to network with influencers who discuss about the activity assigned to them in their blogs.

- Widgets and applications- some platforms permit the making and presentation of widgets and applications on their platforms. Popular widgets are either funded or new ones created to meet the necessities of the users. These widgets are mainly boosted by the media sites.

- Brand pages- they are virtual spaces where products are marketed by highlighting the features of the same and where promotional campaigns are undertaken. They may be screen savers, games, wallpapers, etc. 
- Gifting- virtual gifts like cakes, cards, chocolates are offered to motivate the users. These are immensely popular and go viral instantly.

- Other promotional opportunities- branding opportunities include funding different spaces of social platform or applications, contests, campaigns, share database details for research and merchandising.

RFP (request for proposals) the vendors: After finalising the social platform and target audience, request for proposal (RPF) may be initiated. They are feasible only in high budget marketing programs. Some hints to be considered when issuing RPF.

- Describe the objectives explicitly- Social platforms are keen on getting business, in fact, they are helping the marketers to position their brands among the audience. There is a need to describe the objectives unambiguously to build involvement and trust.

- Be clear about the benchmarks for success- social platforms need to be communicated regarding the parameters of success. They too are accountable for the marketing success and would be held liable. They may consider opting out of RPF than hurt their credibility.

- Recognise that you are getting free advice- when initiating the RPF process, social platforms expect a fair and transparent dealing. They prove their credentials, give ideas and put in a lot of energy in responding to the proposal. So the marketers need to be appreciative of them and should give them an immediate response.

- Beware that you can be limited by who you RPF- when issuing RPF, the participants must be chosen meticulously. A wide search need to be undertaken by including different kinds of medium.

- Evaluate and plan strategically

Planning is the stepping stone to any social influence marketing campaign. Marketers need to be shrewd in identifying the audience and the platforms where they can be found. Interaction with the target customers requires a holistic approach with a keen sense of intuition. The following points need to be included for the process.

- Knowing which social platforms can extend or strengthen your brand- marketers always need to be associated with a credit-worthy platform.

- Having a sense of which social platforms are on the verge of breaking out and growing in size and scale

- Being able to separate the wheat from the chaff- identifying the perfect social media site for campaigning, in others words, separating the best from the rest.

- Thinking beyond audiences and reach- traditional online ads focussed only on the customer. But in social influence marketing, advertising should be centred around the influencers too. Their value and involvement must be considered.

- Being in it for the long run and not getting impatient- results will be reflected only after a considerable long period of wait, especially on the niche platforms. Social influence marketing requires endurance to long waits, to learn and optimize, to test, to develop relationships.

- Thinking holistically and strategically- All the marketing practices both online and offline, must be cohesive and co-ordinated. Immaterial of the size of the media platform, the marketing efforts should focus on the end result.

Moving Beyond the Platforms and the Blogosphere: There are companies who play a pivotal role in generating advertising spaces on media platforms. They are called social platform enhancers. They work closely with the marketers in identifying the motives. Some of them function like an ad agency whereas some work like a software firm which designs widgets and application for blogs and platforms.

Social advertising network: Advertising network is a platform enhancer that solicit advertisement by bringing the audience together. The network can be one application builder who controls a group of applications. In many cases, multiple application builders group together to develop a network and then solicit ads. Through these applications, ads can be placed and promotional campaigns can be undertaken on the desired social platforms. RockYou and MySpace are examples of Social advertising network

Appvertisement providers: Appvertisement providers are also platform enhancers who develop appvertisements for marketers. Appvertisements are a combination of attractive ads powered by useful and entertaining applications. These appvertisements observe a person's online activity and solicits his contributions towards developing a customised application. They are built with features that are social in nature and stimulates the people to install it and request the same to be recommended to others. The appvertisement providers work 
closely with the advertisemnent agency to develop and assures about a certain number of installations on social advertising networks. Gigya, BuddyMedia and ContextOptional are all examples of appvertisement providers.(Shin \& Lee, 2012)

Blogger networks: There are more than 10 million dynamic blogs on the web out of which around 10000 have traffic. However, considering the magnitude of the bloggers, reaching them for marketing efforts will be cumbersome. In such scenario, blogger networks does the role of middlemen bridging the gap between marketer and the blogs by promoting the blogger network and managing the advertiser relations. Many blogger networks give the option of choosing audience and blogs to whom the ads need to be directed to. Some of the popular blogger networks are Federated Media, BlogHer, SixApart, to name a few.

Taking Care of the Unpaid Media Basics: Niche platforms may not always charge for ad campaigns. Though they depend on advertising for income, there are some tactics that can be adopted in the unpaid section. They may not be keen about the ads as long as they do not intrude into the privacy of the user or break the rules of the platform.

- Wikipedia- marketers must refrain from promoting on the main page, instead they can research on how the company or brand is portrayed in Wikipedia. Editing the own page is discouraged as it is considered conflict of interest. Comments are encouraged only on the discussion tab.

- Flickr- this is a photo-sharing website that behaves more like a social networking site. Anyone can post photos of the products and can tag the company. Companies can search the site to get a feel of how their products are presented on the site. However, it is advisable to have their own page to share photos and encourage others to post them too.

- Delicious- this bookmarking site is a space where users store their website bookmarks. Marketers just need to ensure that their corporate websites and brand sites that they own are bookmarked and tagged.

- Digg- it is basically a news sharing site where user can upload any interesting piece of news about the company or product. Depending on the worth, the news item may become popular resulting in free publicity.

- Message boards- helps in understanding the conversation that take place on the message boards. The board specifications determine the participation procedure, the type of discussion and way of dealing with errors.

Accounting for the Influencers: Having already seen in brief the three categories of influencers namely referent, expert and positional, there is a need to study each of them in a detailed manner. To begin with, let us delve deeper into expert influencers.

Basically it covers five types of people

- People in positions of power

- Individuals/ Institutions that are experts in the subject

- Media Moguls- commentators, hosts, journalists

- Cultural icons- celebrities, musicians, artists

- Socially connected people- community leaders, neighbourhood members, business networkers

Ideally, some points that need to be addressed

- Your PR department is already taking care of this- the foremost concern is whether the PR section of the company is taking care to build relationship with these expert influencers. Relationship can be nurtured online through these social platforms. Their activities and conversations can be tracked.

- You are not sure these influencers matter online- sometimes the very need to track these experts is questioned. What does the relationship with them bring into the marketing scenario for small companies? Or do they really need an influencer to promote their business? Or does the expert influencer ever care to develop a relationship with the marketer?

- You have the wrong list of influencers- the final point is the right identification of the so-called experts. People seem to trust their close circle of influencers rather than experts for their purchase decisions. And the credibility and popularity of these experts is dynamic as they keep fluctuating with time.

To sum up, expert influencers need to be first tracked, whether they fit into the 'influencer list' who can impact brand affinity, whether they can and need to be tracked online, whether a relationship need to be nurtured with them, whether existing relationships need to be trusted before approaching experts.

Reaching the Expert Influencers: There are different stages and strategies to reach out and nurture relationships 
with expert influencers. Relationship can begin by introducing oneself to them, by following their tweets or commenting on their pages. As long as the experts attaches a value to the product, they will be interested in the promotion of the product. Relationship with an expert is beneficial to the marketer in the long run. Experts may get acquainted depending on the size of the business, the industry the business is associated with and the product that is required to be sold. Some guidelines to reach out the expert influencers are

- Ask your customers whom they seek out for advice- direct research with the customer on who influences them

- Pay attention to the media - follow the media about the persons frequently highlighted and maintain a database

- Look at your competitive environment- observe who the stakeholders and even competitors turn to for influence and understand those people

- Attend conferences and exhibitions- expert influencers often are invitees at conferences and seminars and they judge new products at these events. It is worth making a note of the keynote speakers

- Seek out the industry analysts- they have enormous influence on the customers who also patronize the products that they endorse. Customers turn to them during the purchase of high worth goods

- Evaluate their online footprint- by doing a research on the ranking of popular blogs gives an insight into the expertise of the blogger and the extent of influence they have on customers. There are many ranking tools like Alexa Scores, Google Page Rank, RSS subscriber numbers which are available to evaluate the blogs.

- Become an influencer yourself- by becoming a leader oneself in the company and community is the best way to become an influencer which also gives access to other influencers.

Tapping into the Referent Influencers: Until recently, referent influencers hardly existed for marketers. There was no system for identifying them or tracking their activities. But the scenario has changed and marketers have realized how important referent influencers are in purchase decision making process. Customers network with their contacts and create a social graph on the platform. Social graphs are the mapping of everyone in this world and their relationship with one another. An individual's social graph refers to those individuals who are linked to that individual and their relationship with each other. Referent influencers may be familiar or unfamiliar people. These referent influencers are a major force behind the buying decision process of an individual. Referent influencers can be categorized into anonymous influencers and known influencers.

- Anonymous referent influencers- they are people who are active on social platforms. Based on their volume of activity on social platforms they are noticed by fellow users

- Known referent influencers- they are familiar with the customers and are members in their social graph

Reaching the Referent Influencers: Marketing to referent influencers require identifying them from the customer's social graph. But it is difficult to access the social graph of users as it is violation of the privacy of the user. However there are enterprise advertising companies seeking solutions to access referent influencers without violation of privacy of the users. These methods are safe although it is expensive. But referent influencers can also be reached on sites like Facebook. By luring the referent influencers with coupons and competitions, they can be asked to encourage and influence the customers. (Fulk, Steinfield, Schmitz, \& Power, 1987)

Social graph analysis: With the aid of database technologies, companies can penetrate into major social networks and access personality, their online activity, their social graph and their friends circle to identify the main influencers. Companies like Unbound Technologies, Rapleaf use parameters like friends list, persuasiveness and influence context measurement to track influencers. By overlapping email database and social graph, influencers can be identified and marketing efforts can be directed at them. (Lee, Kim, \& Ahn, 2014)

Cookie data: Some technology companies analyse cookie data to evaluate relationships between people and direct the ad campaigns at them. If one group of respondents present a favourable attitude towards the ad, then the same ads are targeted at another set of people or to websites or to friends on a similar network. This enables reaching anonymous referent influencer. The limitation of this method is that this promotion can be done only if there is an advertising budget and if it is done online.

Web site behavior: A website is the perfect platform to solicit referent influencers. Starting with the most elementary activity to the most complex ones, website is the apt place for convergence and communication. Once the referent influencers are identified, marketers should ensure that they get the best service available so that they share a favourable image about the product and influence others. They can be incentivised with special offers to build a sense of loyalty. 
Tapping into the Positional Influencers: The final category are the positional influencers who are the closest in relationship to the consumers and the product and purchase affects them directly. But they are the most difficult to identify on social graph. The marketers may not be aware of the role they play as it may vary with the product. The role of the positional influencer too may vary depending on the utility of the product to the buyer. For example, a positional influencer has a bigger role to play in buying a television as it will be also used by that person. Whereas, they may not be concerned when the product bought is not of much interest to them, like, a laptop for spouse's office use. But, it is difficult to identify positional influencers from referent influencers when advertising in a social media space.

Following points allow positional influencers to play the most suitable roles

- Understand the circles of influence around your customers- the people who will be most influenced or affected by the purchase decision need to be identified. Only this data helps in identifying the positional influencers. For example, in the purchase of a high worth product like a car, the spouse is the most important member the purchaser would turn to for assistance, as that person is equally impacted by the purchase of the product.

- Let consumers shape and share the experience- marketers should ensure that access to their websites is simple, in the sense, information can be acquired from the site and can be disseminated to positional influencers. The end result is, the consumers themselves showed the marketers who their influencers are.

- Articulate your product benefits for multiple audiences- marketers should not ignore the influencers at the time of marketing or selling. Once the influencers are identified, design the advertising package to the tune of the influencers too.

- Fish where the fish are- this cliché suits well in the context of buyers accompanied by positional influencers. As already discussed, the buyers themselves show who the positional influencers are. Therefore, marketers must package their campaign to target the positional influencers too, by identifying their online activities too or ensure that the buyers can reach out to the influencers by some feature enabled on the company website itself. For eg, 'Share This' options on websites.

- Badges and promotions- Consumers buy products as a need, a comfort, a status symbol, an identity or for reasons unknown. Whatever be the case, marketers must ensure that the consumers give a favourable image of the product to their peers. For this, consumers must be allowed to use a badge to show their support to the brand. They can place the badge on the blog, on user-profile or the website.

\section{Putting SIM into Action}

Launching SIM Campaigns: A successful SIM (Social Influence Marketing) campaign should behave in sync with other digit marketing campaigns. Marketers must work towards responding positively to criticism and crisis and strengthen the effect of the campaign to last for an extended tenure.

Discovering the Types of SIM Campaigns: A meticulous planning from the marketer's side is required for this. There are different types of campaigns and those that are distinct from those of the competitors are required to capture the attention of the customers. Some of the most commonly used SIM campaigns are listed below.

Blogger outreach: This is the most frequently use SIM campaign. The first step involves identifying the influential bloggers who are also expert influencers and own extremely popular blogs with a huge fan base. Blogger outreach programs target these bloggers and stimulate them to write positively about their product or brand. They are usually incentivised by gifting samples, sending prizes to run competitions on the blogs, inviting them to product launches, etc. Sometimes campaigns are designed to revolve around these popular bloggers. Some bloggers are however not comfortable with the attention showered and refuse compensation whereas some bloggers do not mind the undue attention. So it is important to identify where these bloggers stand in the above categories. Before deciding on the blogger for influencing the brand, a thorough study on how the blog work and the reactions of the followers of the blogger need to be analysed. A relationship can be developed after knowing the contents of the blog. (Keith \& Frese, 2005)

UGC contests: Marketing campaigns keep evolving and the ones that are trending currently is centred on the user generated content (UGC). A contest is run based on the insights contributed by the participants in return for gifts. Sponsored virtual gifts: Sponsored gifts are extremely popular and a major revenue generator for social network platforms. Brands get more user engagement per dollar than through other means of campaigning. It creates a ripple effect where one user encourages other to engage and goes on. There are many virtual reward programs on social networking sites but the ones on Facebook are the most popular. Brand utilities: This works on the premise of giving the customers some utility application instead of an advertisement. When the adopted application is found useful and favourable, users think more positively about the brand. Podcasting: A podcast is a digital audio 
file which is available on web syndication technologies. A podcast by itself is not a social media but assumes as one due to the facility it provides people to organise their own audio files and share them with co-users. It cannot work in isolation in a SIM campaign but works wonders when paired with other SIM campaigns. Sponsored conversations: This is the simplest and effective of all SIM efforts. These campaigns interacts with the consumers directly along with collecting other interactions and befriending a community as a whole.(Hansen et al., 2011)

\subsection{Recognizing What Makes a Good SIM Campaign}

A SIM campaign takes place digitally in the convenience of the user, may be on the social platforms he is conversing. SIM has changed the outlook of marketing campaigns. Previously, the users were lured into spaces dictated by the marketers. But with changing times, marketers are trying to reach to customers at their places of convenience. A few years ago, word of mouth campaigns and display advertisements were hugely popular. The marketers then concentrated on advertising and getting customer on their realms. But now, customers are demanding and do not like to be disturbed or distracted and want the campaigns to be executed at the platforms where they exist. Some of the guidelines to be noted when launching a SIM campaign are as follows.

- Define your objectives- the first and most important step in any program is understanding what to do and how to run the campaign. The objectives must clearly define where to run the campaign, who to target, time-period of the campaign and how it gels with the other marketing efforts. In short, objectives should be pragmatic and action-oriented.

- Execute for influence- the conventional marketing campaigns were aimed only at potential customers and to get the message across only to them. But in SIM campaigns, the aim is to share and influence, reciprocate and get paid for the action. In SIM campaigns, the efforts should be to engage the targeted customers and also get them to share and discuss the campaign with his peers. When the individual shares the campaign, he expects to derive a value from it in the form of offers or status rise, in the sense, the more he shares, the more generation of value is expected.

- Create partnerships- SIM campaigns are successful only when run in partnership between various sources. The campaign must comply with the rules of the media platform it intends to run on, engage with the other large brands that shares the platform and finally the user who tries to establish an ownership of the brand on the platform.

- Track the results- The success or failure of a SIM campaign can be measured in many ways. It depends on the objective, the target and the social platform here the campaign is slated to run. Ideally the measurement techniques have to be decided before the launch of the campaign. The level of influence generated, brand awareness created and if the efforts have resulted in purchase can be measured. With so many tools available in the market, the SIM campaign can be tracked on the website as well as on a physical store.

2.2 Using LinkedIn to Determine Your Objectives and Shape Your Campaign Plan: LinkedIn is an ideal platform for running a SIM campaign to reach out to like-minded professionals

Making connections in LinkedIn: Potential partners can be identified from LinkedIn Service Provider directory. From this people from specific companies can be targeted. Further those individuals who are capable of arranging an introduction with industry experts can be tracked. The following tips can be helpful during the search.

- Pay attention to people's titles- LinkedIn eases the search by briefing about the job title held by the individual and the company associated with him. LinkedIn shows whether the person is connected by one, two or three degrees.

- Join the LinkedIn groups that would appeal to your business- one of the easiest and fastest means of identifying like-minded professionals is by taking membership in a group that is relevant to the industry the marketer is associated with. By this, a lasting reference is created which helps people to identify the marketer.

- Search LinkedIn Answers for people with similar situations as yours- helps to identify people who face the same difficulty as the marketer does and gives insights regarding the people to be approached.

Getting help with your SIM campaign plan using LinkedIn. This online community enable to get practical solutions to the problems faced by professionals without incurring huge costs. Some of the guidelines to be followed to get the best out of LinkedIn are

- Ask targeted questions on LinkedIn Answers - LinkedIn is a perfect platform to solicit answers for queries, as it has many members who are experts in their respective fields. 
- Watch your Question thread closely (through the My Q\&A tab) and provide clarification or responses whenever needed- sometimes there may be an overload of information to a query posted. Sometimes, a clarification on the query may be required. In some cases, the questioner may need to pick a few good answers from an array of answers. This behaviour indicates a reward for the people who have attempted to clear the query. Also it gives hints on which answer suits perfectly to the query.

- Keep the conversation open and continuous- it is advisable to leave the question open-ended to enable people answering them to discuss their views and result in a reason to follow-up with them personally.

- Set up a LinkedIn Group that speaks to your target audience and your company's (or your) capabilitieswhenever specific services are required to be dispersed, grouping similar profiles and staying in touch with the group, in other words, the target audience, will help in knowing them better.

Participating - Four Rules of the Game. There are four main rules that determine the success of SIM campaign.

- Be authentic- it is difficult to define authenticity on social media. In simple terms, it is being honest and transparent, literally. Some examples are

- When you set up a blog as part of your campaign, make sure that you're using your own voice- the content should never be outsourced. If need arises, ensure it is the own voice

- When you're publishing your thoughts, opinions or simply sharing information, don't do so anonymouslyalways reveal the identity to the consumers. People do not like to be associated with anonymous brands and people. There is an unwritten rule in social media that people build relationship with each other and authenticity is pivotal to any relationship.

- Learn from the community and respond to their feedback- feedback is vital in a social media space. The marketers should set aside their space and time to respond to positive and negative feedbacks and answer queries. Participation on social media becomes futile if there is no feedback system

- Be humane in your approach- a person online is a real human. So enough care and consideration should be given as each visitor or comment posted is unique

- Operate on quid pro quo basis- customers will not participate in a SIM campaign if they do not get anything in return. SIM campaign should entertain the customer and motivate him to share it with his contacts and give him due rewards. Success of the ad can be measured by the number of site visits, number of times it was shared and number of times visitors registered for rewards, if any. An example of SIM campaign that provided quid pro quo for its audience was that of a detergent brand that was aired on a popular television show. It was a thirty second ad, directing them to a website and requesting them to forward the video clip. For each share that viewers made, a contribution was made to charity. This was a hugely successful SIM campaign.

- Give participants equal status- marketing campaigns are aimed at people to make them have favourable feelings and feel special. This special feeling that they get enables them to participate in many online campaigns. For this, there are many virtual gifting programs. A user uses the virtual gift and will share it with his peers. This creates a chain reaction, giving and getting of gifts. This reciprocation is the success of any SIM campaign.

- Let go of the campaign- campaigns always take a new shape irrespective of who created it. After a certain point of time, customers take responsibility of moderating the campaign. Successful SIM campaigns take new directions and dimensions. By letting it go allow users to take it to newer directions. However, the creator is in control of the responses to customer involvement.

Killing the Campaign Expiry Date. Unlike the conventional marketing campaigns, there is no specific start date or an end date for a SIM campaign. A SIM campaign may not stop when the marketer wants them to. A brand might have started becoming the topic of interest for a community of people and disowning them would be the last thing that a marketer wants to do. So to divert these community of people towards a broader goal requires sharp business acumen. There are four ways to do it successfully.

- Give participants new reasons to engage with your brand- SIM campaign would have started off with a set of objectives and goals. Once they are accomplished, newer campaigns can be started to cater to this community of people.

- Encourage participants to coalesce into communities- people participate in SIM campaigns if it interests them or if they can identify themselves with the brand. Sometimes, depending on the content of the campaign, people may be interested in forming communities. Those campaigns that has generated goodwill will get converted into customer communities. These are a positive sign for the marketers and can be used for future campaigns. 
- Treat participants like existing customers- there will be participants in a SIM campaign who may not have actually bought the product but would have participated actively like sharing it with friends, commenting on the blog, writing a review and testing a product. As a result, he had spent a lot of his time and energy in engaging with the product. So the marketer owes him and should be treated as a valued customer. To reward him, he may invited to try offers, invitation to be a part of focus groups or testing of a new product.

- Extend the campaign to the Web site- Mostly SIM campaigns take place on micro sites as display ads promoting them. So when the timed out, the campaign is pulled off the site. There is an abrupt end to the campaign. Instead, marketers can always promote the SIM campaign on their corporate site so that customers who have formed communities can find them there.

Monitoring Brands and Conversations. A SIM campaign must always be measured. To do this, there are many tools to measure the success of a SIM campaign. These tools help in creating the campaign, give insights on the user behaviour, what people are discussing with each other in relation to the campaigns and what the target audience is doing on the web. These tools can be divided into three categories

- High-end tools and services - gives a sneak peek into the conversations, the persons who do it and where they do it. These tools are charged based on the number of topics probed and the frequency with which data is mined.

- Low-end tools- they mainly focus on the interactions happening in a specific time period.

- Middle-of-the-road tools - they do some form of analysis but are not as powerful as the high end tools.

- To choose which tools to use, the following factors can be considered

- Your audience- if the audience is unknown and if unsure about their motivations or do not know how and where they are participating, use high end tools.

- The length of your SIM campaign- for a short campaigning targeting limited audience, high end tools are not required as it may be expensive and not worth the money.

- The size of the campaign- when targeting bigger audience high end tools are needed to track users' activities.

- Influencer identification- if the marketers are interested in paying attention to influencers, a tool that is strongest in influencer identification should be chosen.

- Regulatory considerations- when working in a regulated sector, tools that allows viewing activities anonymously should be chosen, like the high end and mid-level tools.

- Dashboard functionality- marketers may require interactive dashboards to keep track of real time conversations. There are a lot of free tools available for monitoring brands and conversations.

Responding to Criticism. Criticisms in a SIM campaign are inevitable. How much ever attractive a campaign may be, it is sure to offend a few set of people. Marketers must be prepared to face criticism and unfavourable responses from people. For this, marketers must adopt a proactive approach. A proper planning is needed at the time of the launch of a campaign regarding the handling of crisis and criticism. The PR department should be roped in for crisis handling and they should work hand in hand to respond to criticism.

A few guidelines will help in tackling criticism.

- Respond early and often- it is always best to respond to criticism at the earliest possible. People who have criticised and who have not got a proper response will feel offended leading to greater anger that can percolate throughout the web.

- Respond honestly and clearly- always adopt a genuine approach by disclosing the identity. Just as the marketer was genuine in his marketing efforts, he needs to be genuine in his responses too. Be affirmative wherever needed and apologetic when wrong.

- Be prepared to change based on the feedback- marketing will be at its best if constructive criticism is accepted and changes incorporated in the campaign. It wins hearts and trust of the participants.

- Don't hesitate to bring humour to the situation- to mitigate unpleasant feelings, a dose of humour is effective. Humorous responses are a big hit on the web and can snowball into a popular SIM campaign.

- Use the same channels for the response- never resort to any other channel or medium for giving a response to a criticism. Stick on to the same channel. 


\subsection{Energizing Employees within Your Company for Social Influence}

Enterprise softwares were used mostly by business managers to for internal communication, handle customer relationship, knowledge management and company operations. Though these softwares were used by employees more than the managers, emphasis was placed on the needs of managers and not on the needs of the users, that is, employees. These employees were efficient enough to design softwares for their personal use and hence managers found an opportunity in this arena. The need to design consumer-centric softwares arose, resulting in Enterprise 2.0. There was a necessity to address and practice social influence marketing within the company, because before practicing it with customers, it is better to start by implementing it at the employee level and encourage them to positively influence one another.

Encouraging Your Employees to Collaborate. Andrew McAfee, a Harvard Business School professor, defines Enterprise 2.0 as the use of social software platforms within companies or between companies and their stakeholders. These softwares are built on the inputs from the internet and are used for collaborating, organising and sharing data. Specifically they function on consumer -oriented design features and the employees too are encouraged to incorporate these philosophies into their work environment.(Kim \& Choi, 2013)

Energizing employees: It's nothing new. Organisations often worked on how to get the best out of their employees. Employees are encourage to collaborate and share their knowledge and expertise so that the performance is at its best and the system does not suffer, in case the employees leave the job. Employees are energised and are given opportunities to collaborate, share and motivate to enhance creativity and performance.

Rewarding teams. To create a conducive work environment, always encourage team performance rather than individual achievements. This nurtures a collaborative work environment where employees are motivated to share knowledge, learn from others and participate in social spheres.

Treating everyone equally. Constructive competition is very effective in getting the best performance out of the employees. However, there may be many employees who may be ignored from the loop. These isolated employees are demoralised and will not put in their best efforts in work. This creates a destructive situation. To avoid such a scenario, always treat employees equally and encourage them to share their grievances with the company management on platforms convenient to them.(Lee et al., 2014)

- Trusting your employees. Employees must be trusted which enable them to perform better towards achieving the business objectives. It is imperative to energise them for social influence, only then will the employees be committed and productive.

- Creating the right culture. A good and open culture is vital for any organisation to succeed. It is the duty of any company management to create a humble, vibrant and transparent work environment where employees can be encouraged to engage in meaningful discussions, learn from mistakes, open to ideas and rewards creativity and innovation.

Placing a premium on groups with a purpose. A group of people with diverse experience and ideas should be assembled together to brainstorm and come to up with a new and creative task. The diversity in the team will result in unique results.

Avoiding excessive snooping. Employees prefer autonomy and privacy in what they do. They do not like to be watched and tracked at every move they take. There should be a culture of social and intellectual conversation and engagement. Always respect them and the employees will deliver amazing performance. (Van Eperen \& Marincola, 2011)

Picking Social Software for Social Influence. Businesses are bombarded with a wide range of tools and softwares that vary in cost depending on what suits the needs of the clients. Finding the right software that empowers employees for social influence can be challenging. For this four versions of softwares can be considered

Enterprise software. Employees cannot control the use of softwares in large organisations. There is a need for enterprise software upgrades that incorporate social functionality which can be used in enterprise environment or run independently.

- Microsoft SharePoint - collaboration software that integrates Microsoft Office and other Microsoft products

- SAP -handles financial, HR needs, business operations and customer

- IBM - with its web sphere portal helps develop applications that csn be disseminated through portal environment 
- Telligent - community server product and integrates well with the rest of a company's server

Emergent enterprise social software. Emergent enterprise social software products are designed to be collaboration tools incorporating the design ideas, needs and requirements of ordinary people. Ideas are obtained from social media sites like Facebook, YouTube, Wkipedia and Twitter. Confluence, Socialtext and NewsGator are new players. The software solutions are plugged into existing software environments to enable it to work efficiently. These softwares comply with the security guidelines of the companies.the software is either delivered as a service model or is shrink-wrapped. (Tsai \& Men, 2012)

Small-scale social software. Smaller and cheaper softwares designed for smaller companies are called small scale social software. Google's Application Suite is free and works well with Gmail. It shares the same user experience of Google search. Similar applications are

- Zoho- is similar to Google Application Suite but far better in features. It is Web-based encompassing related tools such as project management and a CRM software.

- Traction Software -is rich in functionality and is a combination of blogging with a wiki environment. It is a great solution for knowledge management.

- Wetpaint - a relatively simple application that is designed to ease the development of your own site, share it with a select group of people and collaborate

- 37signals has a distinct set of specific Web tools that can help in running business. From a project management application to a tool that recognises leads, it targets specific needs

Consumer social software. Consumer oriented tools can also be used for business. Platforms like LinkedIn, Facebook, Ning, Slideshare are capable of handling private groups who upload and indulge in discussions. These platforms are more secure than third party tools and plug-ins. In LinkedIn, third party plug-ins enable sharing, publishing and collaborating data within the members of LinkedIn

\subsection{Applying Metrics to the SIM Realm}

There is a myth that Social Influence Marketing (SIM) is relatively new to marketing and that it is impossible to be measured. The fact is SIM is as measurable as any other campaign with an array of tools and techniques. There are broader brand metrics and specific campaign or program-oriented metrics. The specific metrics can be in the form of an online community initiative, viral video campaign, a blogger reach initiative or a sharing widget. But most importantly, there has to be a correlation between these metrics with other marketing parameters. So the complexity lies in not measuring the effectiveness of the campaign but in correlating the metrics to the marketing objectives and interpreting

A Core Measure of Social Influence Marketing. Consider a single metric and map it against the Social Influence Marketing (SIM) objectives. This gives the SIM score. Unlike the Net Promoter Score which is a loyalty metric, SIM score is a brand performance metric combined with consumer interactions. But marketers are yet to come to a consensus on the ideal metric for measurement. The SIM scores give insights into the participatory nature of branding and specifically, the overall health of the brand compared to the competitors. SIM score is calculated based on two parameters.

- The reach of the brand, that is, the conversations surrounding the brand

- The consumer sentiment towards the brand, that is, the positive/negative opinions about the brand

The four important factors about SIM Score are

- This is a relative score versus your competitors- the competitors need to be chosen carefully and judiciously as they impact the score. So SIM is a subjective measurement

- The SIM score combines positive and neutral sentiment- neutral opinions too should be accounted for measuring score

- The sourcing and quality of the data that you use to compute the SIM score may directly affect the total scoresthe input for calculations is obtained from the firms like Visible Technologies, TNS Cymfony, Nielsen Buzzmetrics and ScoutLabs that specialise in monitoring conversations where the brand mentions and sentiments (opinions) are analysed.

- Some monitoring vendors let you capture mixed conversations, too- these include both negative and positive opinions. Mixed conversations do not contribute towards brand and hence the number should be included in the denominator in the formula. 
The data acquired from monitoring firms may not be accurate and complete. This is because they do not capture all conversations across different platforms. Platforms like Facebook do not give complete access to capture conversation. However, most of the vendors are capable of capturing conversations from major blogs, forums and community sites. So it gives a near accurate measure. Along with the actual metrics, expert opinions can be sought to determine how the brand is performing in comparison to its competitors. Wetpaint and The Altimer Group combined to develop a framework to rank the leading brands.(Armano, Trovisco, Bodzewski, Greenleigh, \& Balduzzi, 2011)

Considering Influencer-Specific Metrics. It is important to measure how the brand performs on different platforms and how the influencers view them. As already discussed, the influencers play a pivotal role in the brand's image and success. How to measure the favourability of influencers is a challenging task. However, there are some tips for measurement surrounding different type of influencers.

- Expert influencers- after identifying these influencers, their online activities should be tracked to determine their comments about the brand. The conversational monitoring firms through their unique tools track the attitude of these influencers towards the brand

- Referent influencers- Companies like Unbound Technologies and Rapleaf identifies the profiles of people who mentions the brand. Then they map these too the graph to analyse if these people have influenced the target audience in some forms through their conversations or post.

- Positional influencers- firms like Clearspring and Gigya track the widgets that are downloaded. This helps in identifying the positional and referent influencers.

After tracking the influencers and their favourability towards the brand, the next step is identifying if they really are initiating conversations on vital web platforms. To measure this, Google is working towards developing an influencer rank for everyone, based on the extent of influence they have had on their co-users, where they are participating and what they are interested in.

\subsection{Evaluating Each Platform's Metrics}

Different measurement mechanisms exist for different social media platforms. When a SIM campaign is launched, measurement parameters can be broadly divided into four criteria.

- Traffic- Includes impressions, unique visitors and basic involvement including page views per visit.

- Demographics- profile of who visits or interacts with the brand normally includes age, gender, income, education, and location.

- Sociographic -customers' friends and their relative importance, based on their interests and their position in customers' social graphs.

- Social actions- Includes the actual social activity of the customers when they interact on the social platform specifically what they do on the social space

Tracking of competitors' metric is vital and a study of how their Facebook page, Twitter accounts and MySpace profiles engage with customers need to be analysed.

\subsubsection{Facebook}

If the company has a fan page on Facebook, the following parameters can be measured

- Number of fans- fans are the users on the Facebook page who have supported the brand. They more the fans the more popular the brand. On the Facebook page, the user demographic can be ascertained. Campaigns can be undertaken as it enables brands to reach a huge audience

- Page Interactions- page interactions of the fans matter a lot to the brand. Facebook helps in tracking the following metrics from a page

- Total interactions- the number of comments, posts and fan-conversation

- Interactions per post- aggregate number of comments and interactions that each post generate

- Post quality-quality of each post. Higher post quality indicates deeper engagement with the brand

- Stream CTR-stream click through rate(CTR) and engagement click through rate measure the number of people engaging with the data in newsfeed

- Discussion posts- number of topics that have come up for discussion among fans

- Reviews- number of times fans rate the page using review page application 
From the profile page of Facebook user, data regarding those who have added application tab, added application profile box to their profiles, added application information section, bookmarked the application and subscribed to application mails can be obtained. Metrics like active number of users for a specific time period, canvas page views, number of unique users. Average HTTP request time, average FBML can be ascertained. The number of times the name of the brand appears in a conversation can be measured. Lexicon on Facebook gives details regarding number of conversations for the brand and advanced features like sentiments, demographic trends, pulse and location on a map is obtained. With so many metrics available, marketers should know what these imply and how it impacts business. The developers having the most installations of their applications are Zynga, Playfish, RockYou!, Slide, Inc. and LivingSocial.(Reuben, 2008)

\subsubsection{YouTube and video clips}

YouTube Insight gives access to details of clips published and viewer numbers. It gives the following statistics

- Views- the total number of views for the clip. Also seen by the public. The tool shows you the number of unique visitors and the number of location based views. Helps in ascertaining if the people watching the clips belong to the target market.

- Demographics-data based on age, gender, etc

- Community- people who have interacted with the clips, that is, comments, ratings, statistics which can be exported from YouTube Insights to a spreadsheet. These statistics can also be narrowed down by location or video

- However, these statistics may not be sufficient to get an accurate data. Some metrics that are provided by analytics companies are

- E-mail and embed reports-gives details on the number of times the video clip was e-mailed to someone or embedded on a blog or a Web site.

- Link intelligence- gives details on who is linking to the video clips. Links from blogs and traditional websites are accounted

- Aggregation of data: Allows viewing of aggregate statistics on several video clips at a time. For example, access of aggregate data on clips that belong to a single campaign is permitted. Also facilitates tracking of time viewed, viewer attention, per-stream quality, syndication tracking and player tracking.

\subsubsection{Twitter}

A lot can be measured on Twitter as it uses an open Application Programming Interface. There are many analytical tools built on Twitter to measure the reach and frequency of tweets. But the drawback is that it is impossible to identify the demographics of the audience who read the tweets and if at all the tweets are read by the target audience. Those that can be measured from Twitter are

- Brand mentions- the frequency and mentions of the brand can be scanned. This gives a picture of the volume of tweets generated surrounding the brand. TweetVolume does the job of measuring brand mentions on Twitter.

- Influence- tool like Twinfluence measures the reach, frequency, velocity and social worth of people or brand on Twitter. The potential of the brand on Twitter is measured on the basis of who retweets them, who follows the brand and who the brands follow. Twitter Grader calculates the rank of the user relative to other users.

- Pass along and click throughs- continuous scanning of tweets with brand mentions help to understand the role the influencers have played. Tweets can be tracked using tools like TweetDeck which enables multiple search terms. To monitor tweets and retweets, Tweetlist can be used. Those tweets that result in clicks to the website can also be ascertained using bitly and Tweetburner. The number of users tweeting on an time basis and leads generated through Twitter compared to other search engines are all ascertained using advanced tools. Application tools for Twitter are easy to develop as it has a user friendly and flexible API.

\subsubsection{The blogosphere.}

Next to Facebook, most interactions happen on blogs. There are millions of blogs with billions of posts. So identifying brand mentions from these millions of posts is challenging. There are some metrics that need to be identified from the blogosphere. They are

- Number of brand mentions compared to those of competitors

- Ratio of comments and trackbacks

- Frequency of posts and comments on the blogs of the brand as well as those on the competitors 
- Ranking of the blogs mentioning the brand

- Number of conversations made by unique visitors about the brand

- Number of tweets and retweets

\subsubsection{Widgets and Social Applications}

Apart from those on Facebook, widgets and application on other platforms on the internet should be accounted. Some of the key metrics to be considered are

- Installs- the number of people who have installed the application

- Active users- the number of users working on the application in a given time period

- Audience profile- demographics of the users

- Unique user reach- the percentage of users who have installed the application to the total audience

- Growth- percentage increase in user number in a given time period

- Influence- number of familiar users who have installed the application

- Application/widget installation- number of widgets a user has on the profile

- Active users/widgets in the wild- the number of people using widgets on a regular basis.

- Longevity/lifecycle- the duration of usage of an application between installation and uninstallation

Another application used to understand brand health in the social Web is Status Search This application allows search within the Twitter and Facebook contacts' statuses.

\subsubsection{Website community metrics}

When designing a new website for the purpose of SIM, planning the measurement tactics need to be thought about. Rather than keeping track of number of users to the website, their behaviour has to be monitored. For this, the following metrics should be accounted

- Traffic- number of people visiting the community pages or discussion pages of the website.

- Members- the number of people registered on community pages for the purpose of publishing content and reviews

- Interactivity- the number of people involved in the discussion and the frequency with which it happens

- Civility- the tone, the language and ways of expressing opinions, the mutual respect and trust

- Content- those information or posts that are worth reading and sharing

\subsubsection{Other metrics to consider}

To analyse SIM score, there is a need to monitor the metrics on all social platforms other than the major sites. The following should be tracked

- How much the brand and its associated Web sites are bookmarked on sites like Delicious and Flickr

- Alexa, Compete and Quantcast rankings

- Brand mentions on discussion spaces and on other community Web sites like CafeMom and the microblogging service FriendFeed

\section{Suggestions and Conclusions}

Social Influence Marketing (SIM) efforts may fail for numerous reasons. But there is hardly any discussion on why the campaign failed. The following practices may brighten up the chances of succeeding in SIM campaigning.

Open Up Your Brand to Your Consumers and Let Them Evolve It. Immaterial of the goodwill or popularity tag attached to a brand, marketers must learn to allow the customers direct the SIM campaign. Non-flexibility from the marketers' side in shaping the campaign of the brand may run the risk of getting alienated from the customer. Keeping the objectives and appropriateness of the method of functioning of the brand, marketers must facilitate the process of brand transformation. The more the customers are empowered to identify themselves with the brand, the more successful the SIM campaign will shape into. The transformation must be in conformity with the company values and customer expectations.

Develop a SIM Voice without Silencing Other Voices that Support Your Brand. A strong understanding of 
interpersonal skills is vital for SIM campaigns. Sim campaigns must typically involve a more humane and personal touch. Exclusive one sided promotion of the brand and apathy towards critics is highly unacceptable in a SIM campaign. The idea is to reach out to the customers without ending up like a bully. Customer feedbacks and criticism should be constructively dealt with.

Respond to Everything, Even If It Means You're up All Night. From a marketers' perspective, it takes a lot of time and energy to sit through the interactions and participate in the feedback process. It is a tiresome exercise involving impatient customers from many different regions who expect prompt and timely responses to their queries, feedbacks and criticisms. Their attention is fragmented and getting to please them is a cumbersome task. To assist in managing responses, establishing a good relationship with customers online is inevitable. A good rapport should be built especially with the influencers, in case, there is a need for the marketer to go offline, influencers can take the responsibility of the role.

Think Beyond the Obvious and Use SIM to Evolve Your Business. SIM can be used in all spheres of business ranging from marketing, learning from customers, redesigning customer service, incorporating customer views in product development and change the mode of interaction with stakeholders. To assume that social influence is marketing alone, then the marketers are mistaken. Considering the fact that customer behaviour is dynamic, it is important to find creative avenues to reach customers better. Customers are influencing each other through social platforms and there is an unbelievable transformation in the ways people are creating and catering content, entertaining and getting entertained and using technology to make their lives comfortable.

Focus Not Just on Social Media but on Social Influencers. Social platforms are all about interacting with each other. Just because a brand has run a marketing campaign on social platforms does not guarantee success or sales. What is important is tracking the interactions that take place on these platforms. There are people observing and talking about the brand in the virtual space. So, marketers need to shift their focus to these influencers. These are the most powerful salesforce. The influencers have the highest brand affinity and greatest impact on customers' purchasing decisions. Marketers need to move beyond the social media shell and accommodate the influencers into their SIM campaign giving them their due priorities.

Structure Your Marketing Department for This Social World. Marketing has evolved over time and what was considered best marketing practices have become obsolete. Mere creation of eye-catching ads, print ads and display ads no longer amuse the customers. In the current context, customers look at brands in a whole new perspective. There should be online and offline presence of the brand. Marketing efforts should be structured to suit to the demands of changing customer needs. The marketing chart needs a makeover, encompassing market research, online promotions, product innovation and direct, real time feedback from customer, all integrated into the system overlapping each other.

Take Your Organization with You, from the CEO to the Field Representative. For a SIM program to succeed, everyone in the organisation, starting from the CEO to the field representative need to join hands and work together. Each employee must influence his own group of contacts and they should be empowered to be the voice of the company. A successful SIM campaign is achieved by taking every employee in this direction. The best way to start the campaign is by surveying the employees and monitoring how they are using social media to carry the efforts forward.

Conduct Many Small Tests Frequently and Build on Each One. Marketers are clueless about how to practice and succeed in SIM programs. As it is a relatively new phenomenon, it is still in the infant stage taking baby steps towards achieving success. The only way to succeed in SIM is by doing small pilot tests and evaluating the results. By learning from mistakes and incorporating the lessons learnt step by step is the ladder to success. Building relationship with the influencers and connecting deeper with the customers is a longer but a safer and assured path to success.

Capture Every Single Piece of Data that You Can. All the SIM efforts must be evaluated. The results will be known if every data gathered is measured. Capture any data related to business ranging from campaigns initiatives, strategies, number of active influencers, number of views for a video clip, decrease in customer service calls, time taken to launch a new product when customers are involved in product innovation process. Data is the ultimate tool for evaluation.

Make Mistakes, but Make Every Effort to Correct Them as Well. SIM involves live interaction with customers. So making mistakes is inevitable. But what is important is rectifying the mistakes made as quickly as possible. Otherwise, it may lead to a crisis that becomes uncontrollable. One of the main attributes that differentiates SIM from other marketing practices is that SIM involves live interaction with customers on a much larger scale. So any action is amplified on the internet. It can make or break a brand. 
In spite of taking all the best efforts, SIM programs may fail. This is because marketers have failed to take enough precautions. The risks are often overlooked. In order to steer away from failure, the following ten mistakes can be avoided.

Encroaching on Customers' Time. Marketers must identify where their customers are spending time on. Customers may have conversations on the platforms they are comfortable with. Once they are accustomed to the features of the platforms, it is difficult to steer them away from it. So marketers must do a background study to find out if their customers would be interested in moving to another platform and start a conversation and manage them. Without understanding this, companies may be creating an empty community.

Your Customers Don't Want to Hear You. Social platforms are an avenue for people to interact with each other on the topics that they find interesting. It is not designed to carry out marketing activities. So brands should attempt to find out if they have permission to participate in the conversation. But the first step itself can be tricky, that is, determining how to engage with the customers, how much trust customers attribute to the brand and how favourable they view the brand. The permission of the customers is needed for engaging in interactions with them. A brand that had been isolated and serious may not get permission for participating in conversations.

Choosing the Wrong SIM Voices. The person engaged in SIM campaigns is going to be the face of the company. So the people involved in SIM campaigns should be credible, knowledgeable, a good communicator and a tech savvy. He should be able to dedicate his time and efforts for SIM conversations. Those who lack authenticity are not welcomed by the participants. An exclusive training need to be imparted underlining the SIM etiquettes.

Not Being Patient. The SIM efforts may not pay off immediately. For a brand to succeed on the social realm, it may take many months of commitment and dedication from the company's side. SIM involves interaction with customers on a real time basis. So it may not be a runaway hit instantly. Making is the customers to carry forward the marketing efforts is the primary goal. Marketers must wait patiently to witness success.

Treating SIM in Isolation. SIM initiative should not be done in isolation. It should be integrated into the other forms of marketing campaigns. SIM should always supplement the other marketing efforts. While designing SIM campaigns, care should be taken to ensure that they work well along with other forms of advertising like displays ads, print ads, TV ads and ads on mobile phones.

Having Only One Approach. When marketing to the influencers, think about the category into which the influencer falls. Referent influencers were never marketed to previously. So they have no expectations regarding this. Positional influencers are of course a big influence on the customer. With regard to expert influencers, the biggest mistake is treating them like a member of the press. The truth is that expert influencers, though share a lot in common with the people of the press, would not like to be treated like one as they operate in a real time virtual world. They appreciate the attention got but expect to work on their own terms.

Thinking of SIM as a Channel. SIM is an entirely new form of marketing and should not be treated like a traditional advertising channel. The strategies, rules and practices are entirely different from those incorporated in a conventional channel.

Don't Plan for the Worst. There may be a PR crisis at some point of time of a SIM campaign. As SIM involves real time interaction with the customers in a direct and genuine manner, there are risks involved which is invisible in traditional advertising. Risks take two forms

- Actual structure of a SIM campaign- a negative response may arise when the customers are asked to do something. The responses might turn out to be provocative or inspiring and may shadow the campaign.

- Unintentionally elicit a visceral reaction-meticulous planning of a crisis is required to prevent a negative snowball effect.

Focusing on One Large Campaign. When planning a SIM campaign, several small initiatives should be planned rather than one single initiative. SIM is about many tiny actions woven together to make an impact. As customers never stay on the same platform, exchange conversation, navigate to another to view a video and then go offline, focus should never be on one big program.

Forgetting to Reward Your Participants. Marketers should never assume that consumers participate readily and generously to online programs. They need to be incentivised and recognised for their participation. The reward is not necessary to be of monetary value. It has to match the level of participation. Rewards can be in the form of discounts, invitations to events and featuring customers on the company website.

\section{Reference}

Anon. (2000). CMM offers digital solutions. Official Board Markets, 76(28). Retrieved from 
http://www.scopus.com/inward/record.url?eid=2-s2.0-0034229170\&partnerID=40\&md5=352066193b2137 d9f09bf0f1389786d3

Armano, D., Trovisco, C., Bodzewski, J., Greenleigh, I., \& Balduzzi, A. A. (2011). Six Social Media Trends for 2011: Interaction. Harvard Business Review, 89(3), P23-25. Retrieved from http://www.redi-bw.de/db/ebsco. $\mathrm{php} /$ search.ebscohost.com/login.aspx?direct=true $\& \mathrm{db}=$ bth $\& \mathrm{AN}=58554763 \&$ site $=$ ehost-live

Barrutia, J. M., \& Echebarria, C. (2013). Networks: a social marketing tool. European Journal of Marketing, 47(1-2), 324-343. https://doi.org/10.1108/03090561311285574

Boyd, D. (2008). Why Youth $\vee \quad$ Social Network Sites.pdf. Digital Media, $119-142$. https://doi.org/10.1162/dmal.9780262524834.119

Boyd, D. M., \& Ellison, N. B. E. (2008). Definition of Social Networking Site: Definition, History, and Scholarship. Journal of Computer-Mediated Communication, 13(1), 210-230. https://doi.org/10.1111/j. 1083-6101.2007.00393.x

Chu, S. C., \& Kim, Y. (2011). Determinants of consumer engagement in electronic Word-Of-Mouth (eWOM) in social networking sites. International Journal of Advertising, 30(1). https://doi.org/10.2501/IJA-30$1-047-075$

Fire, M., Goldschmidt, R., \& Elovici, Y. (2013). Online Social Networks: Threats and Solutions Survey. IEEE Communication Surveys \& Tutorials Online, 16(4), 1-20. https://doi.org/10.1109/COMST.2014.2321628

Fulk, J., Steinfield, C. W., Schmitz, J., \& Power, J. G. (1987). A Social Information Processing Model of Media Use in Organizations. Communication Research. https://doi.org/10.1177/009365087014005005

Gneiser, M., Heidemann, J., Klier, M., \& Landherr, A. (2009). Quantifying Users\&apos; Interconnectedness in Online Social Networks-An Indispensible .... Value Creation in $E$ - ... Retrieved from https://www.springerlink.com/index/Q24M27M6425Q7272.pdf

Guthrie, J., Cuganesan, S., \& Ward, L. (2008). Industry specific social and environmental reporting: The Australian Food and Beverage Industry. Accounting Forum, 32(1), 1-15. https://doi.org/10.1016/j.accfor.2007.10.001

Hansen, D. L., Shneiderman, B., Smith, M. A., Welser, H. T., Underwood, P., Cosley, D., ... Black, L. W. (2011). Analyzing Social Media Networks with NodeXL. Analyzing Social Media Networks with NodeXL. https://doi.org/10.1016/B978-0-12-382229-1.00015-1

Jiang, J. (2006). The role of culture in online organization-publics relationship building: Comparing design and content of corporate Web sites in the United States and China. ProQuest Dissertations and Theses. Retrieved from http://search.proquest.com/docview/305263475?accountid=14549\%5Cnhttp://hl5yy6xn2p.search.seria lssolutions.com/?genre=article\&sid=ProQ:\&atitle $=$ The + role + of + culture + in + online + organization-publics $+r$ elationship+building:+Comparing+design+and+content + of + corpora

Keith, N., \& Frese, M. (2005). Self-regulation in error management training: emotion control and metacognition as mediators of performance effects. The Journal of Applied Psychology, 90(4), 677-91. https://doi.org/10.1037/0021-9010.90.4.677

Kim, D., \& Choi, M. Il. (2013). A Comparison of Young Publics' Evaluations of Corporate Social Responsibility Practices of Multinational Corporations in the United States and South Korea. Journal of Business Ethics, 113(1), 105-118. https://doi.org/10.1007/s10551-012-1285-7

Lee, E., Kim, Y. J., \& Ahn, J. (2014). How do people use Facebook features to manage social capital? Computers in Human Behavior, 36, 440-445. https://doi.org/10.1016/j.chb.2014.04.007

Papacharissi, Z. (2009). The virtual geographies of social networks: a comparative analysis of Facebook, LinkedIn and ASmallWorld. New Media \& Society, 11(1-2), $199-220$. https://doi.org/10.1177/1461444808099577

Patchin, J. W., \& Hinduja, S. (2010). Trends in online social networking: adolescent use of MySpace over time. New Media \& Society, 12(2), 197-216. https://doi.org/10.1177/1461444809341857

Provost, F., Dalessandro, B., Hook, R., Zhang, X., \& Murray, A. (2009). Audience Selection for On-line Brand Advertising: Privacy-friendly Social Network Targeting. Acm, 707-715. https://doi.org/10.1145/1557019.1557098

Reuben, B. R. (2008). The Use of Social Media in Higher Education for Marketing and Communications : A 
Guide for Professionals in Higher Education. Retrieved from Httpdoteduguru comwpcontentuploads200808socialmediainhighereducation $\quad P d f, \quad$ 5(Cavazza), $1-13$. https://doi.org/10.1108/S2044-9968(2012)0000005018

Shin, H., \& Lee, J. (2012). Impact and degree of user sociability in social media. Information Sciences, 196, 28-46. https://doi.org/10.1016/j.ins.2012.01.040

Tsai, W.-H. (Sunny), \& Men, L. R. (2012). Cultural values reflected in corporate pages on popular social network sites in China and the United States. Journal of Research in Interactive Marketing, 6(1), 42-58. https://doi.org/10.1108/17505931211241369

Van Eperen, L., \& Marincola, F. M. (2011). How scientists use social media to communicate their research. Journal of Translational Medicine. https://doi.org/10.1186/1479-5876-9-199

Wey, T., Blumstein, D. T., Shen, W., \& Jordán, F. (2008). Social network analysis of animal behaviour: a promising tool for the study of sociality. Animal Behaviour. https://doi.org/10.1016/j.anbehav.2007.06.020

\section{Copyrights}

Copyright for this article is retained by the author(s), with first publication rights granted to the journal.

This is an open-access article distributed under the terms and conditions of the Creative Commons Attribution license (http://creativecommons.org/licenses/by/4.0/). 